\title{
Effect of fiberoptic bronchoscopy on respiratory performance in patients with chronic airways obstruction
}

\author{
B. G. S A L I B U R Y, L F. METZG ER, M. D. A L T OSE, \\ N. N. S T A NLEY, and N.S. CHER N I A C K
}

Pulmonary Disease Section, Department of Medicine, Hospital of the University of Pennsylvania, Philadelphia

\begin{abstract}
Salisbury, B. G., Metzger, L. F., Altose, M. D., Stanley, N. N., and Cherniack, N. S. (1975). Thorax, 30, 441-446. Effect of fiberoptic bronchoscopy on respiratory performance in patients with chronic airways obstruction. Lung volumes, airway resistance, expiratory flow rates, distribution of ventilation, and arterial blood gases were measured before and after fiberoptic bronchoscopy in 13 patients with moderately severe chronic airways obstruction and in 10 healthy non-smoking controls. Arterial blood gases were also monitored serially during the procedure. Arterial oxygen tension $\left(\mathrm{PaO}_{2}\right)$ fell during fiberoptic bronchoscopy in both patients and controls whereas arterial carbon dioxide tension and $\mathrm{pH}$ remained unchanged. Control subjects had no change in lung mechanics after fiberoptic bronchoscopy. However, the patients consistently developed increased airway obstruction after fiberoptic bronchoscopy. Within 24 hours after bronchoscopy lung function in the patients returned to baseline values, except for the residual volume which remained abnormally high. The topical application of lignocaine (Lidocaine) for local anaesthesia before fiberoptic bronchoscopy produced no effect on lung mechanics in nine patients and 10 controls, but $\mathrm{PaO}_{2}$ decreased in both the patient and control groups. These results indicate that fiberoptic bronchoscopy consistently impairs lung mechanics and gas exchange in patients with chronic airways obstruction but that the impairment is mild and reversible. Lignocaine administration as well as the intubation procedure contribute to the fall in $\mathrm{PaO}_{2}$ which occurs both in the patients and in subjects without pre-existing lung disease.
\end{abstract}

The introduction of fiberoptic bronchoscopy has simplified the direct examination of central as well as peripheral airways and is now in widespread use for diagnosis and therapy. Of practical interest is the extent to which the procedure may increase the respiratory disorder in patients with chronic airways obstruction. In these patients, obstruction of the airway by the bronchoscope, bronchospasm, respiratory depression related to premedication, and suctioning may all have serious adverse effects because of the underlying abnormalities in lung mechanics and gas exchange (Credle, Smiddy, and Elliott, 1974). Previous studies of the effect of bronchoscopy on pulmonary performance have been confined to measurements of blood gas tensions during fiberoptic bronchoscopy or rigid bronchoscopy (Forke,
Schoemperlen, and Cherniack, 1962; Dubrawsky, Awe, and Jenkins, 1973; Harrell et al., 1973; Kleinholz, Fussell, and McBrayer, 1973). The present paper describes a more comprehensive appraisal of the effect of fiberoptic bronchoscopy on pulmonary mechanics and gas exchange in patients with moderately severe chronic airways obstruction and in normal volunteers.

\section{METHODS}

Thirteen patients with chronic airways obstruction and 10 normal controls were studied before and after fiberoptic bronchoscopy. The patient group consisted of 10 men and three women with a mean age of 59 (range 43-73) years. All patients had a smoking history of greater than 30 pack 
years, chronic productive cough, dyspnoea, and wheeze during forced expiration. The chest radiograph of most patients suggested that the lungs were hyperinflated. Only those patients with an elevated airway resistance $\left(R_{a w}\right)$ at functional residual capacity (FRC) were included in the study. The normal volunteers consisted of nine men and one woman with the mean age of 28 (range 21-43) years. All volunteers were nonsmokers with no past history of pulmonary disease and with normal pulmonary function studies. Informed consent was obtained from each individual before the start of the studies.

Pulmonary function studies were performed before, 15 minutes after, and 24 hours after bronchoscopy. They included determinations of lung volumes, flow rates, airway resistance $\left(\mathbf{R}_{\mathbf{a w}}\right)$, single breath nitrogen washout, and closing volume. Spirometry was performed using a Collins 13.5 litre spirometer with the subject in the sitting position. The expiratory curves were analysed for vital capacity (VC), forced vital capacity (FVC), and one-second forced expiratory volume $\left(F_{E V}\right)$. The $F R C$ and $R_{\text {aw }}$ were measured with the body plethysmograph (DuBois et al., 1956). The single breath nitrogen washout was performed according to the method of Comroe and Fowler (1951). Closing volume was measured as described by Anthonisen et al. (1969) modified with an expiratory resistance to keep flow less than $0.51 /$ second. All tests were performed in triplicate and the best value was used. All results were corrected to BTPS. For closing volume and single breath nitrogen washout, the mean value of those tracings in which the expired volume was within $5 \%$ of the forced vital capacity was used. Predicted values for lung volumes (Goldman and Becklake, 1959), flow rates (Boren, Kory, and Syner, 1966), airway resistance (Briscoe and DuBois, 1958), closing volumes (McCarthy et al., 1972), and single breath nitrogen washout (Comroe and Fowler, 1951) were utilized. Statistical significance was determined by the paired $t$ test.

An arterial cannula was inserted in the brachial artery and a baseline arterial blood sample was collected. The $\mathrm{PaO}_{2}, \mathrm{PaCO}_{2}$, and $\mathrm{pH}$ were determined by appropriate electrodes (Radiometer Corporation). Patients and control subjects were then premedicated with meperidine $(50-75 \mathrm{mg})$ and atropine $(0.4-0.6 \mathrm{mg})$ intramuscularly 30 minutes before bronchoscopy. The pharynx and pyriform sinuses were anaesthetized by topical application of $2 \%$ lignocaine; one nostril was similarly anaesthetized with $4 \%$ lignocaine. A flexible bronchofiberscope (Olympus BF/5B2) was then passed transnasally into the trachea and $1 \mathrm{ml} \underset{\overrightarrow{\mathrm{F}}}{\overrightarrow{\mathrm{s}}}$ adiquots of $2 \%$ lignocaine were injected through the aspiration channel of the bronchoscope as $\frac{}{0}$ needed for suppression of the cough reflex. $\frac{\overline{\bar{N}}}{\bar{n}}$ Arterial blood samples were collected serially $\widehat{\phi}$ during bronchoscopy while the tip of the bronchoscope was located in the trachea, mainstem ${ }^{\infty}$ bronchus, a lobar bronchus, and a segmental $\vec{\circ}$ bronchus. Arterial blood samples were not drawn $\overrightarrow{\vec{\omega}}$ during suctioning. Arterial blood samples were ${ }_{\sigma}^{\omega}$ also collected 15 minutes after completion of the $\overrightarrow{\vec{x}}$ procedure (or later if the $\mathrm{PaO}_{2}$ failed to return to baseline values).

Because our initial results indicated that significant changes in lung mechanics and gas exchange $\$$ occurred during fiberoptic bronchoscopy in the 0 patients, the effect of topical lignocaine administration alone on pulmonary function was deter $-\triangle$ mined. In nine patients and 10 control subjects, 0 $5 \mathrm{ml}$ of $2 \%$ lignocaine $(100 \mathrm{mg})$ was administered by a Bird micronebulizer. This dosage is well $\overrightarrow{\vec{\theta}}$ within the safe limits of lignocaine administration (Thomson et al., 1973). Pulmonary function studies were performed before and 15 minutes after administration, and arterial blood gases were monitored at five-minute intervals for 45 minutes after administration.

\section{RESULTS}

Control subjects had no significant change in lung volumes, forced expiratory flow rates, airway? resistance, and closing volume after fiberoptic bronchoscopy. In contrast, the patients demon-음 strated changes in lung volumes and mechanicscon- $-\frac{\hat{x}}{x}$ sistent with increased airway obstruction (Table). $\dot{0}$ As shown in Fig. 1a, VC fell (mean \pm SE) $13 \pm 3 \%$. $(P<0.001)$ and RV increased $12 \pm 7 \% 15$ minutes after fiberoptic bronchoscopy. In three patients, the reduction in VC exceeded $20 \%$ while in threeo other patients, RV increased by more than $33 \%$. The mean increase in FRC in all the patients waso $7 \pm 3 \%$. Additionally, as shown in Fig. 1b, Raw increased $23 \pm 5 \% \quad(P<0.01)$ and FEV $_{1}$ declined $O$ $10 \pm 4 \%(P<0.05)$. The fall in $F^{2} V_{1}$ in threeN patients was more than $20 \%$. Fiberoptic broncho-N scopy also resulted in a fall in airway conductance $\left(\mathrm{G}_{\mathrm{aw}}\right)(\mathrm{P}<0.01)$ which tended to be more pro-co nounced in those patients with the highest baseline $\frac{\text { }}{\mathbb{C}}$ $\mathbf{G}_{\mathrm{aw}}$ and less marked in individuals with the most? severe airways obstruction. Thus the percent change in $G_{a w}$ in all the patients $(17 \pm 3 \%)$ waso much the same regardless of the extent of their ${ }_{\Omega}^{\mathbb{\Phi}}$ disease. These changes were associated with a worsening of the distribution of ventilation as 


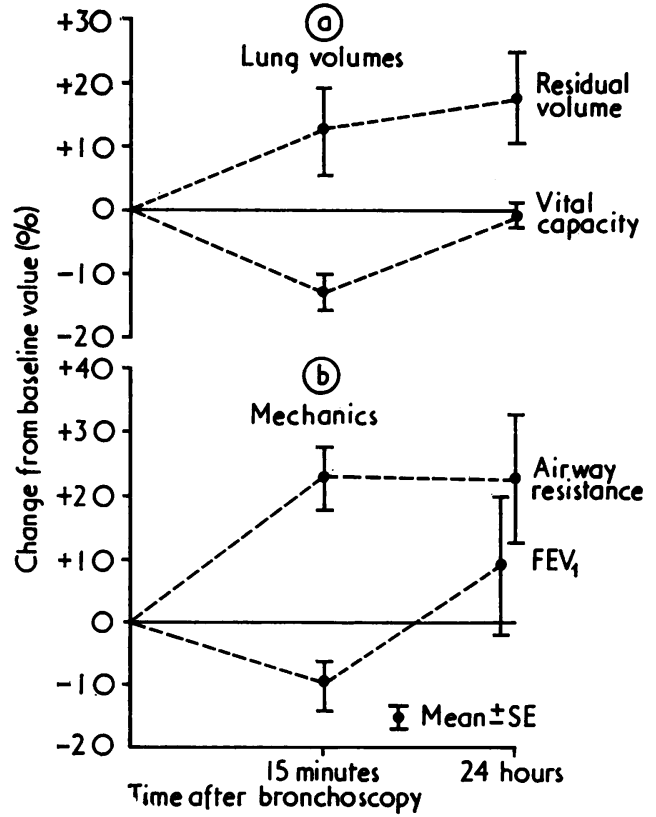

FIG. 1. Percent change from baseline values in (a) lung volumes and (b) airway mechanics in 13 patients 15 minutes and 24 hours following bronchoscopy.

assessed by the single breath nitrogen washout $(P<0.025)$. Closing volume could not be determined in most of the patients.

Twenty-four hours after fiberoptic bronchoscopy all indices had returned to baseline values except RV which remained significantly elevated $(P<0.05)$. Although the increased $R_{a w}$ persisted 24 hours after the procedure, the change from baseline values was not statistically significant.

There was a decrease in $\mathrm{PaO}_{2}$ during fiberoptic bronchoscopy both in the patients $(10 \pm 3 \mathrm{mmHg}$, $P<0.01)$ and in the control subjects $(12 \pm 3 \mathrm{mmHg}$, $\mathbf{P}<0.05$ ) without any significant change in $\mathrm{PaCO}_{2}$ and $\mathrm{pH}$ (Fig. 2a and Table). Three of the volunteers had decrements in $\mathrm{PaO}_{2}$ of more than $15 \mathrm{mmHg}$ and two of the patients had reductions in $\mathrm{PaO}_{2}$ of $22 \mathrm{mmHg}$ at the same or lower $\mathrm{PaCO}_{2}$. In one of these patients $\mathrm{PaO}_{2}$ dropped from 60 to $38 \mathrm{mmHg}$ while the pulse rate increased from 90 to 110 ; there were no extrasystoles. In the same patient, the alveolar-arterial oxygen gradient during bronchoscopy increased from 26 to $51 \mathrm{mmHg}$ although the dead space to tidal volume ratio remained unchanged. The alveolar-arterial oxygen gradient returned to $30 \mathrm{mmHg}$ immediately after extubation as the $\mathrm{PaO}_{2}$ rose to $58 \mathrm{mmHg}$. The fall in $\mathrm{PaO}_{2}$ in the patients during fiberoptic bron-

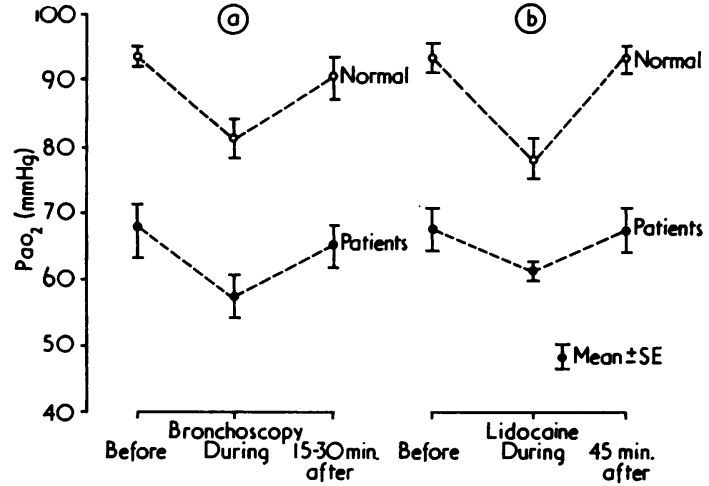

FIG. 2. (a) Changes in arterial oxygen tension during and 15 to 30 minutes after fiberoptic bronchoscopy in 10 normal individuals and 11 patients, and (b) changes in arterial oxygen tension 15 minutes and 45 minutes after administration of Lidocaine in 10 normal individuals and nine patients.

choscopy was not related either to the degree of hypoxia or to the severity of airway obstruction.

Serial arterial blood samples were obtained during the course of bronchoscopy, as the bronchoscope was advanced from the trachea to the segmental bronchi. There was an initial drop in $\mathrm{PaO}_{2}$ as the trachea was entered in both the patients and the controls, but no consistent pattern thereafter (Fig. 3). $\mathrm{PaO}_{2}$ did not decrease significantly with time during bronchoscopy (Fig. 4). Nor did $\mathrm{Paco}_{2}$ or $\mathrm{pH}$ change during bronchoscopy even in those patients with $\mathrm{CO}_{2}$ retention before bronchoscopy. Repeat measurements 15 to 30 minutes after bronchoscopy failed to show any significant difference in $\mathrm{PaO}_{2}$ from pre-bronchoscopy values in either group.

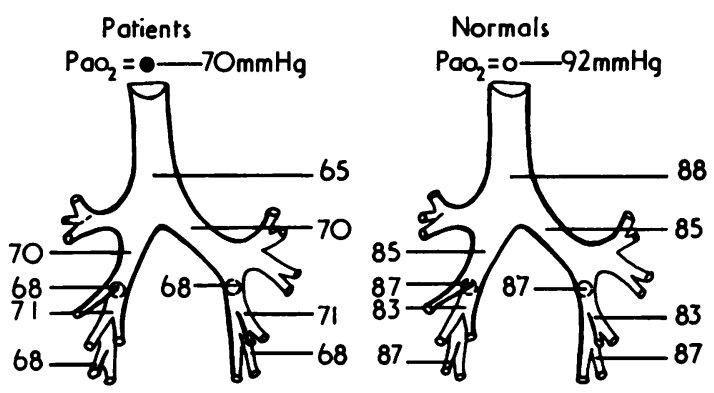

FIG. 3. Arterial oxygen tension with the tip of the bronchoscope positioned in the designated location in the tracheobronchial tree. Each value represents the mean arterial oxygen tension in (left) 11 patients and (right) 10 normal individuals. 
T A B L E

MEAN VALUES \pm SE FOR LUNG MECHANICS AND GAS EXCHANGE DATA IN THE PATIENTS AND CONTROL SUBJECTS

\begin{tabular}{|c|c|c|c|c|c|c|c|c|c|c|c|c|}
\hline & \multicolumn{8}{|c|}{ Mechanics and Distribution of Ventilation } & & \multicolumn{3}{|c|}{ Gas Exchange } \\
\hline & $\begin{array}{l}\text { VC } \\
\text { (l.) }\end{array}$ & $\underset{\text { (I.) }}{\text { FRC }}$ & $\begin{array}{l}\text { RV } \\
\text { (1.) }\end{array}$ & $\begin{array}{c}\text { TLC } \\
\text { (1.) }\end{array}$ & $\underset{\text { (1.) }}{\text { FEV }_{1}}$ & $\mathbf{R}_{\text {aw }}$ & $\mathrm{G}_{\mathrm{aw}}$ & $\Delta \% \mathrm{~N}_{2}$ & & $\underset{(\mathrm{mmHg})}{\mathrm{PaO}_{2}}$ & $\begin{array}{l}\mathrm{PaCO}_{2} \\
\mathrm{mmHg})\end{array}$ & pH \\
\hline $\begin{array}{l}\text { Patients } \\
\text { Before } \\
\text { bronchoscopy } \\
15 \text { min after } \\
\text { bronchoscopy } \\
24 \text { hr after } \\
\text { bronchoscopy }\end{array}$ & $\begin{array}{r}2.71 \\
+0.19 \\
2.39 \\
+0.21 \\
2.61 \\
+0.24\end{array}$ & $\begin{array}{r}4.32 \\
+0.35 \\
4.54 \\
+0.28 \\
4.75 \\
\pm 0.36\end{array}$ & $\begin{array}{r}3.32 \\
+0.30 \\
3.62 \\
\pm 0.24 \\
3.81 \\
+0.33\end{array}$ & $\begin{array}{r}6.03 \\
+0.37 \\
6.01 \\
+0.24 \\
6.42 \\
+0.21\end{array}$ & $\begin{array}{r}1.37 \\
+0.16 \\
1.18 \\
+0.16 \\
1.39 \\
+0.16\end{array}$ & $\begin{array}{r}3 \cdot 3 \\
\pm 0 \cdot 3 \\
4 \cdot 1 \\
\pm 0 \cdot 3 \\
3 \cdot 9 \\
\pm 0 \cdot 4\end{array}$ & $\begin{array}{r}0.34 \\
+0.04 \\
0.28 \\
\pm 0.03 \\
0.30 \\
\pm 0.04\end{array}$ & $\begin{array}{r}3.9 \\
+0.8 \\
5.3 \\
\pm 0.9 \\
3.8 \\
\pm 0.8\end{array}$ & $\begin{array}{l}\text { Before } \\
\text { bronchoscopy } \\
\text { During } \\
\text { bronchoscopy } \\
15 \text { min after } \\
\text { bronchoscopy }\end{array}$ & $\begin{array}{r}66 \\
+4 \\
58 \\
\pm 3 \\
66 \\
\pm 4\end{array}$ & $\begin{array}{l}42 \\
\pm 2 \\
41 \cdot 5 \\
\pm 3 \\
43 \\
\pm 2 \cdot 7\end{array}$ & $\begin{array}{r}7.40 \\
\pm 0.02 \\
7.41 \\
+0.02 \\
7.41 \\
\pm 0.01\end{array}$ \\
\hline $\begin{array}{l}\text { Control Subjects } \\
\text { Before } \\
\text { bronchoscopy } \\
15 \text { min after } \\
\text { bronchoscopy } \\
24 \text { hr after } \\
\text { bronchoscopy }\end{array}$ & $\begin{array}{r}5.59 \\
+0.25 \\
4.96 \\
+0.55 \\
5.80 \\
+0.29\end{array}$ & 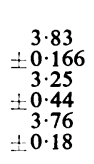 & $\begin{array}{r}1.89 \\
\pm 0.11 \\
1.73 \\
\pm 0.20 \\
1.61 \\
\pm 0.18\end{array}$ & $\begin{array}{r}7.48 \\
+0.34 \\
6.69 \\
+0.31 \\
7.41 \\
+0.36\end{array}$ & $\begin{array}{r}4.59 \\
+0.25 \\
4.55 \\
+0.23 \\
4.8 \\
+0.31\end{array}$ & $\begin{array}{r}1.7 \\
\pm 0.1 \\
1.5 \\
\pm 0.1 \\
1.6 \\
\pm 0.1\end{array}$ & $\begin{array}{r}0.59 \\
\pm 0.04 \\
0.66 \\
\pm 0.03 \\
0.62 \\
\pm 0.06\end{array}$ & $\begin{array}{r}0.66 \\
+0.22 \\
0.88 \\
+0.22 \\
0.66 \\
\pm 0.28\end{array}$ & $\begin{array}{l}\text { Before } \\
\text { bronchoscopy } \\
\text { During } \\
\text { bronchoscopy } \\
15 \text { min after } \\
\text { bronchoscopy }\end{array}$ & $\begin{array}{l}94 \\
\pm 1.6 \\
82 \\
\pm 2.6 \\
91 \\
\pm 3.0\end{array}$ & $\begin{array}{r}40 \cdot 3 \\
+8 \\
38 \cdot 7 \\
\pm 1 \cdot 6 \\
39 \cdot 2 \\
\pm 1 \cdot 1\end{array}$ & $\begin{array}{r}7.40 \mathrm{c} \\
\pm 0.005 \\
7.39 \\
\pm 0.02 \\
7.39 \\
\pm 0.02\end{array}$ \\
\hline
\end{tabular}

Definition of Abbreviations

$\mathrm{VC}=$ vital capacity; $\mathrm{FRC}=$ functional residual capacity; $\mathbf{R V}=$ residual volume; $T$ LC $=$ total lung capacity; $F E V_{1}=$ forced $_{\text {expiratory }}$ volume in 1 second; $R_{\mathrm{aw}}=$ airway resistance at functional residual capacity; $\mathrm{G}_{\mathrm{aw}}=$ airway conductance; $\Delta \% \mathrm{~N}_{2}=$ percent change in nitrogen concentration in expired air from 750 to $1250 \mathrm{ml} ; \mathrm{PaO}_{2}=$ arterial oxygen tension; $\mathrm{PaCO}_{2}=$ arterial carbon dioxide tension; $\mathrm{pH}=$ arterial $\mathrm{pH}$.

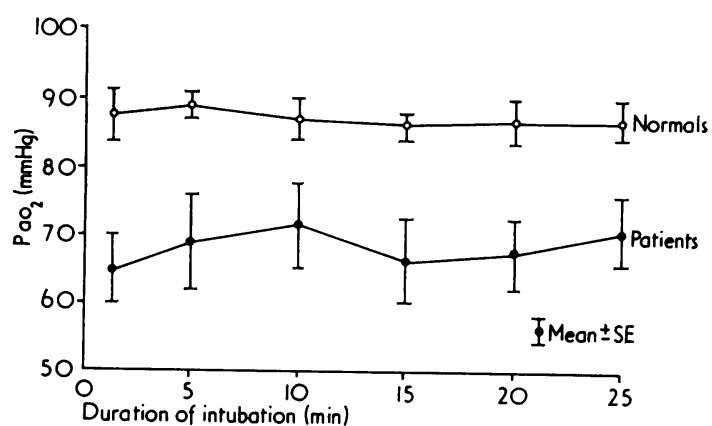

FIG. 4. Relationship between mean arterial oxygen tension in 10 normal individuals and 11 patients and the duration of intubation.

The effect of topical lignocaine anaesthesia on lung mechanics and arterial blood gas tensions was determined in nine patients and 10 control subjects. Fifteen minutes after administration, there was no significant effect on lung mechanics in either group but $\mathrm{PaO}_{2}$ fell in both groups (patients $6 \pm 2 \mathrm{mmHg}, \quad \mathrm{P}<0.01$; control subjects $15 \pm 3$ $\mathrm{mmHg}, \quad \mathrm{P}<0.01$ ) without significant change in $\mathrm{PaCO}_{2}$ or pH (Fig. 2b). This decline in $\mathrm{PaO}_{2}$ after lignocaine anaesthesia lasted for only five to 10 minutes.

\section{DISCUSSION}

The present study indicates that fiberoptic bronchoscopy results in a mild, transient increase in airway obstruction and abnormal distribution of ventilation in patients with chronic airway obstruction but not in normal subjects. These changes in lung mechanics seem to be secondary to the bron: choscopic intubation since administration of topical lignocaine by nebuliser had no significant effect on lung volumes, flow rates, airway resistance, or closing volume. Although there were nos changes in lung mechanics following fiberoptic bronchoscopy in normal individuals, the patients demonstrated significant increases in airway ob $\frac{\mathbb{D}}{\square}$ struction with the greatest absolute changes in $\mathbf{G}_{\mathrm{aw}}$ in those with the mildest obstruction and possibly the most sensitive airways. At the time of bronchoscopy most of our patients did not haves significant secretions, presumably as a result of previously adequate bronchial toilet. Thereforeo bronchospasm rather than increased secretions is the most likely cause of the progressive airwayo obstruction.

Twenty-four hours after fiberoptic bronchoo scopy, despite the return of the vital capacity, $\mathrm{FEV}_{1}$, and $\mathrm{PaO}_{2}$ to baseline values, the elevatedo airway resistance persisted in the patients with chronic airways obstruction. The change in $R_{a} w$ 을. from baseline values, which was not statistically significant, probably resulted from persistent naro rowing of intrapulmonary airways but it is pos $N$ sible that mild laryngeal oedema could have contributed to the increased resistance.

Arterial blood samples monitored during fiberoptic bronchoscopy showed a decline in $\mathrm{PaO}_{2}$ both in the patients and in control subjects without any significant change in $\mathrm{PaCO}_{2}$ or $\mathrm{pH} .0$ The hypoxaemia was transient with a rapid returno of $\mathrm{PaO}_{2}$ to baseline levels by 15 to 30 minutes after, fiberoptic bronchoscopy. In the patients, the decline in $\mathrm{PaO}_{2}$ during bronchoscopy may beo 
caused by ventilation-perfusion inequalities associated with progressive airway obstruction. Hypoventilation is not a factor since there was no significant change in $\mathrm{PacO}_{\text {. }}$.

The decline in $\mathrm{PaO}_{2}$ in the patients during fiberoptic bronchoscopy $(10 \pm 3 \mathrm{mmHg})$ is less than the mean drop of $20 \mathrm{mmHg}$ reported by Albertini, Harrel, and Moser (1974) in a group of patients with unspecified lung disease. Harrell et al. (1973) reported that the duration of the bronchoscopy and the amount of secretions tended to have been greater in those who had a significant drop in $\mathrm{PaO}_{2}$. In the present study, bronchoscopy time averaged 25 (range 15 to 40 ) minutes compared to a bronchoscopy time of less than 15 minutes in the report of Harrell et al. (1973). Arterial oxygen tension did not decrease significantly with time nor with location of the bronchoscope after the initial reduction in $\mathrm{PaO}_{2}$ that followed entry into the trachea. The amount of secretions may be responsible for the quantitative difference in decrement of $\mathrm{PaO}_{2}$ during fiberoptic bronchoscopy between the two studies. Suctioning and lavage with large quantities of saline may also potentiate hypoxaemia during fiberoptic bronchoscopy (Dubrawsky et al., 1973). Arterial oxygen tension was not measured during suctioning, and large quantities of saline were not used since secretions were not troublesome.

During fiberoptic bronchoscopy, the normal volunteers also had a significant decrease in $\mathrm{PaO}_{2}$ unrelated to duration of the procedure or to the position of the bronchoscope. However, the normal pulmonary function studies were determined 15 minutes after bronchoscopy, after $\mathrm{PaO}_{2}$ had already returned to normal. Therefore the present study does not exclude the possibility that transient abnormalities in airway dynamics had occurred but had reversed by the time that the measurements of mechanics were made.

The data on nebulized lignocaine may distinguish between the effects of the local anaesthetic and the bronchoscopic intubation as contributory factors in the decreased $\mathrm{PaO}_{2}$ during bronchoscopy in the patients and normal volunteers. Transient hypoxaemia, often lasting only five to 10 minutes, occurred in both groups after lignocaine administration. The cause of the arterial hypoxaemia appears to be ventilation-perfusion inequalities since $100 \%$ oxygen breathing corrected the hypoxaemia in several controls and demonstrated no significant shunt. Since $\mathrm{PacO}_{2}$ did not increase at the time of maximal decrease in $\mathrm{PaO}_{2}$, alveolar hypoventilation cannot explain the hypoxaemia.

Two lines of evidence suggest that the ligno- caine effect may well be due to the instillation of liquid into the tracheobronchial tree rather than to a pharmacological effect of lignocaine. During lignocaine administration, tidal volume, respiratory frequency, mean pulse, and mean arterial blood pressure (monitored via the arterial line) failed to change in three patients and three control subjects. Moreover, nebulization of isotonic saline in these same patients produced similar falls in $\mathrm{PaO}_{2}$.

These results suggest that fiberoptic bronchoscopy causes a statistically significant but small impairment in lung mechanics and gas exchange in patients with chronic airways obstruction. The absence of symptoms and the small quantitative changes in lung mechanics after bronchoscopy in patients with moderately severe airways obstruction (mean $\mathrm{FEV}_{1}=1.31$ ) indicate the safety of the procedure if adequate oxygenation is provided during the bronchoscopy. Lignocaine administration as well as the intubation procedure contributed to the fall in $\mathrm{PaO}_{2}$ both in the patients and in subjects without pre-existing lung disease.

We thank Dr. Alfred P. Fishman for his valuable advice in the preparation of this manuscript.

This study was supported by grants from the National Heart and Lung Institute (HL-08805 and HL-15061-03) and by Pulmonary Disease Traineeship Program TR-214.

\section{REFERENCES}

Albertini, R., Harrell, J. H., and Moser, K. M. (1974). Hypoxemia during fiberoptic bronchoscopy (communications to the editor). Chest, 65, 117.

Anthonisen, N. R., Danson, J., Robertson, P. C., and Ross, W. R. D. (1969). Airway closure as a function of age. Respiration Physiology, 8, 58.

Boren, H. G., Kory, R. C., and Syner, J. C. (1966). The Veterans Administration-Army cooperative study of pulmonary function. II. The lung volume and its subdivisions in normal men. American Journal of Medicine, 41, 96.

Briscoe, W. A. and DuBois, A. B. (1958). The relationship between airway resistance, airway conductance and lung volume in subjects of different age and body size. Journal of Clinical Investigation, 37, 1279.

Comroe, J. H. and Fowler, W. S. (1951). Detection of uneven alveolar ventilation during a single breath of oxygen. American Journal of Medicine, 10, 408.

Credle, W. F., Smiddy, J. F., and Elliott, R. C. (1974). Complications of fiberoptic bronchoscopy. American Review of Respiratory Diseases, 109, 67. 
DuBois, A. B., Botelho, S. Y., Bedell, G. N., Marshall, R., and Comroe, J. H. (1956). A rapid plethysmographic method for measuring thoracic gas volume: a comparison with a nitrogen washout method for measuring functional residual capacity in normal subjects. Journal of Clinical Investigation, 35, 322.

Dubrawsky, C., Awe, R. J., and Jenkins, D. E. (1973). Effect of fiberoptic bronchoscopy on oxygenation of arterial blood (abstract). Chest, 64, 393.

Forke, M. E., Schoemperlen, C. B., and Cherniack, R. M. (1962). Alveolar ventilation during bronchoscopy. Diseases of the Chest, 42, 311 .

Goldman, H. I. and Becklake, M. R. (1959). Respiratory function tests: Normal values at median altitudes and the prediction of normal results. American Review of Respiratory Diseases, 79, 457.

Harrell, J. H., Albertini, R. E., Kurihara, N., and Moser, K. M. (1973). Gas exchange abnormalities induced during fiberoptic bronchoscopy (ab- stract). American Review of Respiratory $\stackrel{\overrightarrow{\mathrm{S}}}{\overrightarrow{\mathrm{a}}}$ Diseases, 107, 1091.

Kleinholz, E. J., Fussell, J., and McBrayer, R. (1973). Arterial blood gas studies during fiberoptic bronchoscopy. American Review of Respiratory ${ }_{\overparen{\Phi}}$ Diseases, 108, 1014.

McCarthy, D. S., Spencer, R., Greene, R. and Milic-®ֶ Emili, J. (1972). Measurement of "closing volume" as a simple and sensitive test for early. detection of small airway disease. American $\overrightarrow{ }$ Journal of Medicine, 52, 747.

Thomson, P. D., Melmon, K. L., Richardson, J. A., Cohn, K., Steinbrunn, W., Cudihee, R., and $\times$ Rowland, M. (1973). Lidocaine pharmacokinetics in advanced heart failure, liver disease, and renal failure in humans. Annals of Internal Medicine, 78, 499.

Requests for reprints to: Dr. Murray D. Altose, 음 Hospital of the University of Pennsylvania, 3400Spruce Street, Philadelphia, Pennsylvania, 19104, USA. 